\title{
Effects of fluoroacetate on the testis of the rat
}

\author{
Judith L. Sullivan, F. A. Smith and R. H. Garman \\ Departments of Radiation Biology and Biophysics, and Laboratory Animal Medicine and \\ Pathology, University of Rochester School of Medicine and Dentistry, Rochester, New York, \\ 14642, U.S.A.
}

\begin{abstract}
Summary. Rats receiving $20,6 \cdot 6$ or $2 \cdot 2$ p.p.m. sodium fluoroacetate in the drinking water were killed daily during the 7 days of treatment and at more widely spaced intervals in the succeeding 21 days. Testicular weight and ATP concentrations decreased in rats receiving 20 or 6 p.p.m. fluoroacetate, while citrate concentrations were elevated and morphological damage was seen in the testes of all the treated rats. Initial cellular changes common to the three treatment groups included altered appearance and decreased numbers of spermatids, and formation of spermatid and spermatocyte giant cells. At the two higher concentrations, damage progressed to marked seminiferous tubule atrophy. Regeneration of the seminiferous tubules was complete by 7 days after treatment, in the rats given 2 p.p.m. but regeneration was not complete by Day 21 after treatment in those receiving the higher doses. Spermatogenesis was abnormal in some instances during the regeneration period in these groups. The findings are consistent with impaired energy production via blockage of the Krebs cycle, and subsequent impairment of carbohydrate metabolism through the Embden-Meyerhof pathway.
\end{abstract}

\section{Introduction}

Peters (1952) found that fluoroacetate is converted in vivo to fluorocitrate, a potent inhibitor of the tricarboxylic acid cycle enzyme cis-aconitase. This inhibition produces an accumulation of citrate and often a reduction in the energy available to the cell since the ability to phosphorylate is diminished.

Previous studies have shown that fluoroacetate produces tubular degeneration and elevated citrate levels in the testis (Mazzanti, Lopez \& Berti, 1965), moderate histological change with significant citrate accumulation in the kidney (McDowell, 1972) and little histological change or citrate accumulation in the liver (Buffa, Guarriera-Bobyleva \& Pasquali-Ronchetti, 1972). These results were obtained with various dosing regimens and rat strains and were designed to study the toxic effects on individual organ systems. It was therefore considered that an integrative study of some effects of fluoroacetate on the testis, kidney, and liver of the rat could be of value. In this study, non-lethal concentrations were chosen in an effort to reduce the degenerative processes and to unmask possible changes hidden by a rapid and violent death.

\section{Materials and Methods}

Male Sprague-Dawley rats (Blue Spruce Farm, Inc., Altamont, New York) weighing 165-180 g were used throughout the experiment. Four groups of rats were placed on low fluoride rat chow (Teklab Mills, Madison, Wisconsin) and distilled water for 1 week preceding treatment. Three 
groups then received sodium fluoroacetate (Calbiochem, LaJolla, California) in the drinking water at concentrations of 20 (Group 1), 6.6 (Group 2) and 2.2 (Group 3) p.p.m. for 1-7 days. The fourth group (Group 4) was maintained on low fluoride rat chow and distilled water as a control. After 7 days of fluoroacetate treatment, all rats were again placed on distilled water for 3-21 days.

The rats were killed by an overdose of pentobarbitone sodium and 6/group were killed daily during the 7 days of treatment and at 3, 7, 14 and 21 days after the end of treatment. The animals were fasted for $17 \mathrm{~h}$ before being killed and for this period they were housed in metabolism cages for the collection of urine. Urinary protein concentrations were determined by the method of Lowry, Rosebrough, Farr \& Randall (1951).

At autopsy, the testes, kidneys and liver of each rat were immediately removed and sections of each organ taken for histopathological study. Testes were fixed in Bouin's fluid and stained with haematoxylin and eosin ( $\mathrm{H} \& \mathrm{E})$ and in some cases with periodic acid-Schiff (PAS). Kidney and liver sections were fixed in $10 \%$ neutral phosphate-buffered formalin and stained with $\mathrm{H} \& \mathrm{E}$. The remaining tissue from these three organs was utilized for adenosine triphosphate (ATP) and citrate measurements. For ATP the tissues were homogenized in an equal volume of $12 \%$ trichloroacetic acid plus an equal volume of normal saline $(9 \mathrm{~g} \mathrm{NaCl} / \mathrm{l})$ (1:3 dilution), centrifuged, and the supernatants removed for analysis. ATP was converted to ADP and 1,3-phosphoglycerate and the latter, in the presence of NADH, was converted to glyceraldehyde-3-phosphate and NAD. By determining the decrease in absorbance at $340 \mathrm{~nm}$ resulting when $\mathrm{NADH}$ is oxidized to NAD, a measure was obtained of the amount of ATP present in the sample. Reagents and procedural details used were those supplied in the Sigma Chemical Company (St. Louis, Mo.) Kit No. 366-UV for ATP determination. Citrate was determined according to the method of Moellering \& Gruber (1966) as used by Pashley (1970). The tissues were homogenized with equal volumes of saline, acidified with perchloric acid and centrifuged. Citrate in the supernatant was converted to oxaloacetate with citrate lyase, and the oxaloacetate in the presence of NADH and malate dehydrogenase was converted to malate and NAD. As for ATP, the change in absorbance occasioned by the conversion of NADH to NAD was taken as a measure of the citrate originally present.

\section{Results}

Measurements of the water intake permitted estimations of fluoroacetate ingested by the animals in each group. Rats in Group 1 ( 20 p.p.m.) ingested a daily average of $0.14 \mathrm{mg}$ fluoroacetate/rat $(0.71 \mathrm{mg} / \mathrm{kg})$. Those in Group $2(6.6$ p.p.m.) ingested a daily average of $0.037 \mathrm{mg} / \mathrm{rat}(0.18$ $\mathrm{mg} / \mathrm{kg}$ ), and for those in Group 3 (2.2 p.p.m.) the corresponding figures were $0.016 \mathrm{mg} / \mathrm{rat}$ daily and $0.07 \mathrm{mg} / \mathrm{kg}$. These amounts did not induce overt signs of acute toxicity, e.g. convulsions typical of severe fluoroacetate poisoning.

Mean body weights of the animals in each of the treatment groups were not significantly affected until after 3 days of fluoroacetate ingestion. During the last 4 days of treatment rats in Group 1 gained less weight than did control animals. The Group 2 rats maintained normal body weight until the last day of treatment; those in Group 3 had normal body weights except for those killed on Day 6. Growth of the treated rats remained depressed during the first week of recovery but was normal thereafter for those in Groups 1 and 2. Recovery was slower in Group 3 rats and body weights were still slightly depressed 3 weeks after removing the fluoroacetate from the drinking water.

The effect of fluoroacetate on the testis weight is shown in Table 1. In the animals of Groups 1 and 2 killed 5-6 days after the start of treatment the testes appeared shrunken and flaccid. The organ weight/body weight ratio was significantly depressed at Day 7 in Group 1 and continued 
Table 1. Testis weights (mean \pm s.e.m.) and testis weight/body weight ratio of rats given sodium fluoroacetate in the drinking water on Days 1-7

\begin{tabular}{|c|c|c|c|c|c|c|c|c|}
\hline \multirow[b]{3}{*}{ Days } & \multicolumn{6}{|c|}{ Fluoroacetate-treated rats } & & \\
\hline & \multicolumn{2}{|c|}{ Group 1 (20 p.p.m.) } & \multicolumn{2}{|c|}{ Group 2 (6.6 p.p.m.) } & \multicolumn{2}{|c|}{ Group 3 (2.2 p.p.m.) } & \multicolumn{2}{|c|}{ Group 4 (controls) } \\
\hline & $\begin{array}{l}\text { Testis } \\
\text { wt (g) }\end{array}$ & $\begin{array}{l}\text { Testis: } \\
\text { body wt }\end{array}$ & $\begin{array}{l}\text { Testis } \\
\text { wt (g) }\end{array}$ & $\begin{array}{l}\text { Testis: } \\
\text { body wt }\end{array}$ & $\begin{array}{l}\text { Testis } \\
\text { wt }(\mathrm{g})\end{array}$ & $\begin{array}{l}\text { Testis: } \\
\text { body wt }\end{array}$ & $\begin{array}{l}\text { Testis } \\
\text { wt (g) }\end{array}$ & $\begin{array}{l}\text { Testis: } \\
\text { body wt }\end{array}$ \\
\hline 1 & $2.53 \pm 0.09$ & 0.0129 & $2.63 \pm 0.07$ & 0.0134 & $2.23 \pm 0.11$ & 0.0117 & $2.58 \pm 0.09$ & 0.0133 \\
\hline 2 & $2.72 \pm 0.11$ & 0.0130 & $2.85 \pm 0.09$ & 0.0134 & $2.94 \pm 0.15$ & 0.0127 & $2.61 \pm 0.07$ & 0.0128 \\
\hline 3 & $2.44 \pm 0.15$ & 0.0130 & $2.58 \pm 0.09$ & 0.0131 & $2.50 \pm 0.06$ & 0.0136 & $2.66 \pm 0.09$ & 0.0135 \\
\hline 4 & $2.33 \pm 0.11$ & 0.0123 & $2.55 \pm 0.02$ & 0.0130 & $2.52 \pm 0.10$ & 0.0129 & $2.64 \pm 0.07$ & 0.0129 \\
\hline 5 & $2.36 \pm 0.12$ & 0.0124 & $2.76 \pm 0.02$ & 0.0127 & $2.73 \pm 0.08$ & 0.0132 & $2.69 \pm 0.15$ & 0.0119 \\
\hline 6 & $2 \cdot 41 \pm 0 \cdot 10$ & 0.0115 & $2.63 \pm 0.04$ & 0.0112 & $2 \cdot 68 \pm 0.16$ & 0.0129 & $2.75 \pm 0.17$ & 0.0123 \\
\hline 7 & $1.82 \pm 0.17$ & $0.0100^{*}$ & $2 \cdot 28 \pm 0.23$ & 0.0121 & $2.85 \pm 0.07$ & 0.0121 & $2.93 \pm 0.07$ & 0.0129 \\
\hline 10 & $1.57 \pm 0.09$ & $0.0073^{*}$ & $1.68 \pm 0.07$ & $0.0079^{*}$ & $2.89 \pm 0.07$ & 0.0129 & $3.03 \pm 0.08$ & 0.0130 \\
\hline 14 & $1.53 \pm 0.17$ & $0.0067^{*}$ & $1.47 \pm 0.07$ & $0.0062^{*}$ & $2.54 \pm 0.20$ & 0.0103 & $3.27 \pm 0.10$ & 0.0116 \\
\hline 21 & $1.49 \pm 0.11$ & $0.0051^{*}$ & $1.89 \pm 0.29$ & $0.0061^{*}$ & $3 \cdot 15 \pm 0 \cdot 11$ & 0.0112 & $3.32 \pm 0.13$ & 0.0106 \\
\hline 28 & $1.50 \pm 0.08$ & $0.0047^{*}$ & $1.73 \pm 0.20$ & $0.0053^{*}$ & $3.23 \pm 0.08$ & 0.0105 & $3.37 \pm 0.18$ & 0.0101 \\
\hline
\end{tabular}

* Values significantly different from the corresponding control value, $P<0.005$.

to decline throughout the recovery period. In Group 2 the ratio was not significantly affected until after treatment was stopped, but it then remained depressed throughout the recovery period. Fluoroacetate had little or no effect on testicular weight or appearance in Group 3.

All concentrations of fluoroacetate used produced significant histological changes in the testis. To evaluate these changes, use was made of the staging method of Leblond \& Clermont (1952), utilizing sections stained with $\mathrm{H} \& \mathrm{E}$ or PAS.

The dosing regimen used did not bring about a single specific degenerative change in the testis, but rather a spectrum of changes was induced. All concentrations of fluoroacetate ingested in the drinking water produced the following early changes: kinking and clubbing of elongated spermatid heads (Pl. 1, Fig. 1) primarily in the late stages (stages X-XIV) but also often in the early stages (I-V); depletion of late spermatids in these same stages (I-V, X-XIV) (Pl. 1, Fig. 2); giant cells formed of early round spermatids (Pl. 1, Fig. 3) primarily in the early stages, and of spermatocytes (Pl. 1, Fig. 4) primarily in the later stages. Tubular degeneration characterized by a loss of the normal tubular pattern, individual cell necrosis, and exfoliation of cells into the tubular lumina (P1. 1, Fig. 5) made it impossible to stage many of the tubules in affected testes. However, in the early stages of testicular degeneration, there was a definite sparing of those tubules in stages VI-VIII. These changes were first noted after 2, 3, and 4 days of treatment in Groups 1, 2 and 3 respectively.

The testicular changes in Group 3 rats were not as widespread as those in Groups 1 and 2: some testes in Group 3 were histologically normal at each time point sampled and only the acute degenerative changes were evident, there being no evidence of spermatocyte depletion or of seminiferous tubule atrophy. By 7 days after treatment, all testes in rats in Group 3 were histologically normal.

In Groups 1 and 2, increasing degrees of damage resulting in marked tubular atrophy were noted at the end of treatment. Atrophic tubules had only a basal layer of Sertoli cells with abundant fibrillary cytoplasm and occasionally a few scattered spermatogonia (Pl. 1, Figs 7, 8 and 9). Evidence of early regeneration characterized by the reappearance of primary spermatocytes was noted in both groups by 7 days after treatment. By 21 days, elongated spermatids and mature spermatozoa were present in some tubules (Pl. 1, Fig. 6), although many tubules were still markedly atrophic. 
Table 2. Mean \pm s.e.m. citrate concentrations in testes of rats given different concentrations of sodium fluoroacetate in the drinking water on Days $1-7$

\begin{tabular}{ccccc}
\hline \multicolumn{4}{c}{ Citrate $(\mu \mathrm{g} / \mathrm{g})$} \\
\cline { 2 - 5 } Days & $\begin{array}{c}\text { Group 1 } \\
(20 \text { p.p.m.) }\end{array}$ & $\begin{array}{c}\text { Group 2 } \\
(6 \cdot 6 \text { p.p.m.) }\end{array}$ & $\begin{array}{c}\text { Group 3 } \\
(2 \cdot 2 \text { p.p.m.) }\end{array}$ & $\begin{array}{c}\text { Group 4 } \\
\text { (controls) }\end{array}$ \\
\hline 1 & $206 \pm 50^{\mathrm{a}}$ & $101 \pm 29$ & $16 \pm 1$ & $64 \pm 4$ \\
2 & $479 \pm 60^{\mathrm{c}}$ & $254 \pm 44^{\mathrm{c}}$ & $58 \pm 3$ & $69 \pm 5$ \\
3 & $449 \pm 20^{\mathrm{c}}$ & $217 \pm 28^{\mathrm{c}}$ & $124 \pm 9^{\mathrm{c}}$ & $70 \pm 3$ \\
4 & $471 \pm 31^{\mathrm{c}}$ & $296 \pm 30^{\mathrm{c}}$ & $139 \pm 12^{\mathrm{c}}$ & $62 \pm 5$ \\
5 & $367 \pm 21^{\mathrm{c}}$ & $261 \pm 31^{\mathrm{c}}$ & $155 \pm 15^{\mathrm{c}}$ & $74 \pm 3$ \\
6 & $414 \pm 44^{\mathrm{c}}$ & $245 \pm 45^{\mathrm{b}}$ & $139 \pm 15^{\mathrm{c}}$ & $77 \pm 4$ \\
7 & $221 \pm 31^{\mathrm{c}}$ & $229 \pm 28^{\mathrm{c}}$ & $172 \pm 34$ & $87 \pm 17$ \\
10 & $62 \pm 5$ & $69 \pm 3$ & $167 \pm 20^{\mathrm{a}}$ & $91 \pm 15$ \\
14 & $67 \pm 16$ & $90 \pm 11$ & $87 \pm 3$ & $76 \pm 5$ \\
21 & $69 \pm 11$ & $65 \pm 6$ & $86 \pm 2$ & $83 \pm 3$ \\
28 & $57 \pm 10$ & $72 \pm 7$ & $70 \pm 1$ & $79 \pm 7$ \\
\hline
\end{tabular}

Values with superscripts are significantly different from the corresponding control group; ${ }^{\text {a }} P<0.05,{ }^{\text {b }} P<0.02,{ }^{\mathrm{c}} P<0.01$.

There was no evidence, in any of the groups, of interstitial cell degeneration. In testes in which there was significant tubular atrophy, the interstitial cells were actually more prominent, but this was probably a result of tubular shrinkage with increased interstitial space. While the possibility of interstitial cell hyperplasia could not be ruled out, individual cell hypertrophy and mitotic figures were not observed. The accessory sex glands were not examined histologically.

Marked citrate accumulation $(P<0.05)$ occurred in the testes of all the treated rats (Table 2 ) and seemed to parallel histological changes, with the levels returning to control values during

\section{EXPLANATION OF PLATE 1}

Fig. 1. High power photomicrograph of testis after 4 days exposure to 6.6 p.p.m. fluoroacetate, showing clubbing of spermatids (arrows) at approximately stages X-XI. H \& E, $\times 432$.

Fig. 2. Depletion of spermatids, tubule in stage approximately XI-XIII, after exposure for 2 days to 20 p.p.m. fluoroacetate. $H \&$ E, $\times 432$.

Fig. 3. Testis after 6 days of exposure to 6.6 p.p.m. fluoroacetate, showing spermatid giant cell formation. Spermatozoa are still present in the lower (stage VII) tubule. H \& E $\times 230$.

Fig. 4. Testis after 4 days of exposure to 6.6 p.p.m. fluoroacetate, showing binucleate (small arrow) spermatocytes and spermatocytic giant cells (large arrow). H \& E, $\times 432$.

Fig. 5. Degenerating seminiferous tubule after 4 days of exposure to 6.6 p.p.m. fluoroacetate, showing the generalized disorganization, loss of nuclear detail, increased cytoplasmic eosinophilia and exfoliation of cells. This type of tubule is impossible to stage accurately. $\mathrm{H} \& \mathrm{E}, \times 432$.

Fig. 6. Section of testis after exposure to 20 p.p.m. fluoroacetate for 7 days followed by 14 days recovery, showing a mixture of atrophic tubules (1), tubules in early stages of regeneration (2), and a nearly normal stage VIII tubule (3). $\mathrm{H} \& \mathrm{E}, \times 115$.

Fig. 7. Normal testis of a control rat. $\mathrm{H} \& \mathrm{E}, \times 115$.

Fig. 8. Testis of rat exposed to 20 p.p.m. fluoroacetate for 7 days, then allowed to recover for 7 days. Note the seminiferous tubular 'atrophy', a late stage of tubular degeneration, characterized by cell loss and tubular shrinkage with widening of the interstitial space, compared with Fig. 7 . Spermatidal giant cells are still present. $\mathrm{H} \& \mathrm{E}, \times 115$.

Fig. 9. Testis after exposure to 6.6 p.p.m. fluoroacetate for 7 days followed by 21 days recovery, showing an 'atrophic' tubule containing only spermatogonia (solid arrows) and Sertoli cells (open arrows). The latter have extensive fibrillary cytoplasm. H \& E, $\times 432$. 


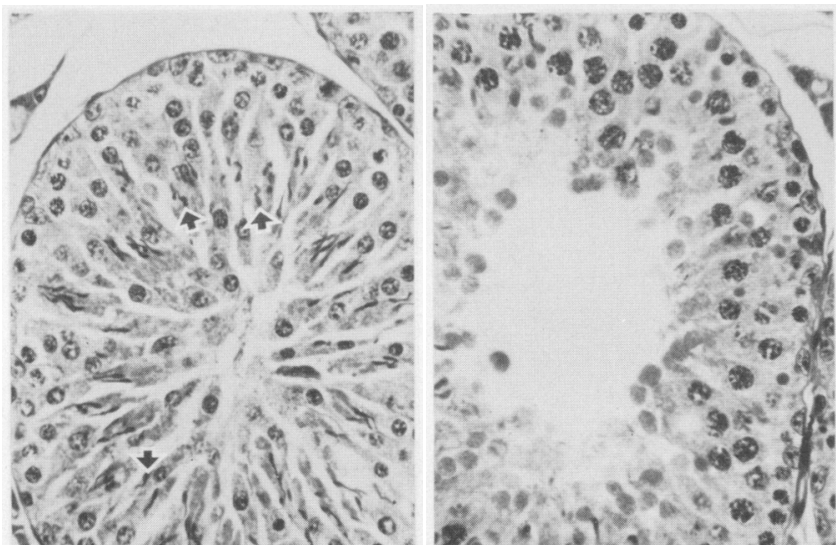

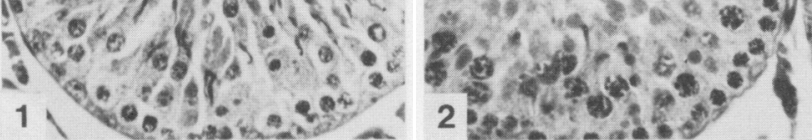

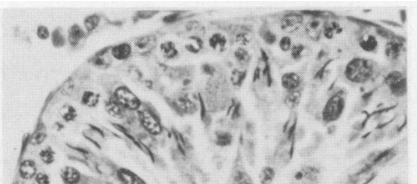

$0 \%$

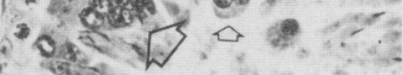
(5)

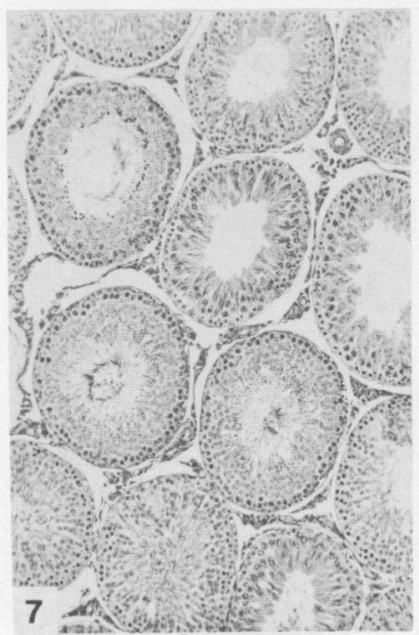

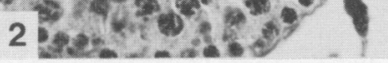
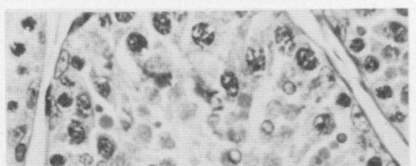

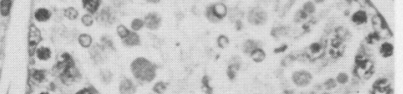

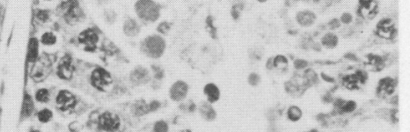
b.

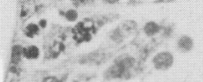

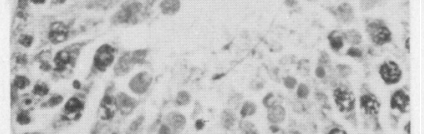
(8. o. ois as:

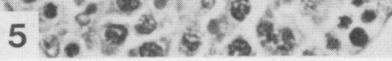

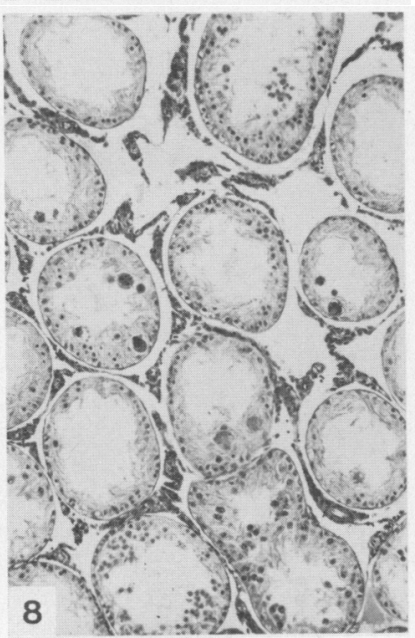

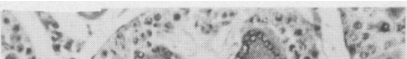
$\therefore p^{2}$ a $\because 0^{2} \quad$ का

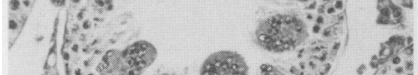

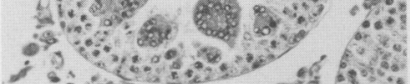

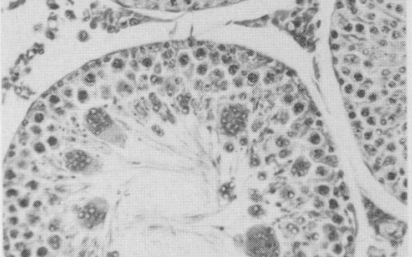
80300 $40 \%, 30.9$

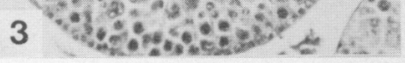
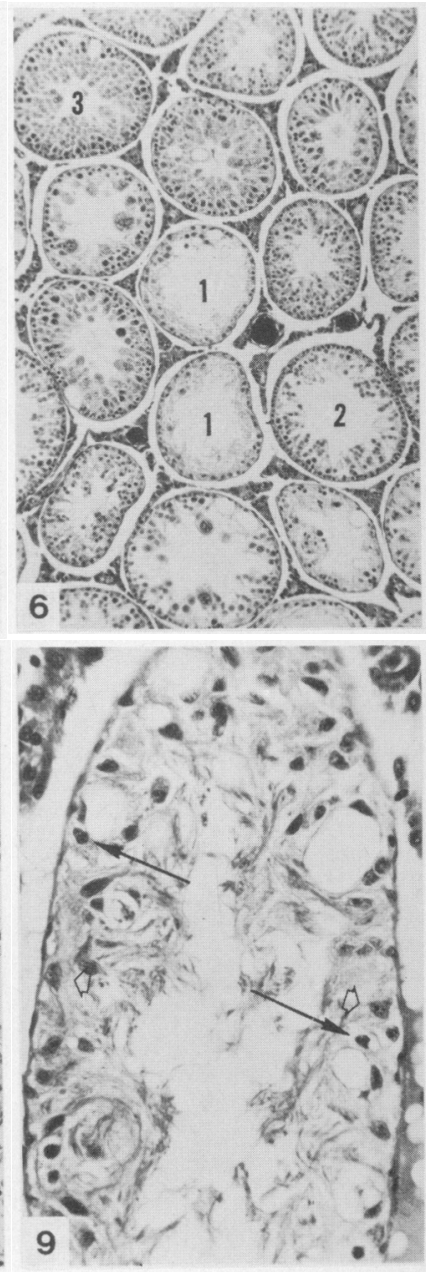
Table 3. Mean \pm s.e.m. ATP concentrations in testes of rats given different concentrations of sodium fluoroacetate in the drinking water on Days 1-7

\begin{tabular}{rcccc}
\hline & & \multicolumn{2}{c}{ ATP $(\mu \mathrm{mol} / \mathrm{g})$} \\
\cline { 2 - 5 } Days & $\begin{array}{c}\text { Group 1 } \\
(20 \text { p.p.m.) }\end{array}$ & $\begin{array}{c}\text { Group 2 } \\
(6.6 \text { p.p.m.) }\end{array}$ & $\begin{array}{c}\text { Group 3 } \\
(2.2 \text { p.p.m.) }\end{array}$ & $\begin{array}{c}\text { Group 4 } \\
\text { (controls) }\end{array}$ \\
\hline 1 & $1.72 \pm 0.07$ & $1.80 \pm 0.10$ & $1.87 \pm 0.08$ & $1.85 \pm 0.09$ \\
2 & $1.33 \pm 0.14^{\mathrm{b}}$ & $1.72 \pm 0.08$ & $1.79 \pm 0.04$ & $1.87 \pm 0.08$ \\
3 & $1.14 \pm 0.09^{\mathrm{b}}$ & $1.51 \pm 0.04$ & $1.79 \pm 0.09$ & $1.56 \pm 0.10$ \\
4 & $0.950 \pm 0.046^{\mathrm{c}}$ & $1.14 \pm 0.02^{\mathrm{c}}$ & $1.47 \pm 0.06$ & $1.51 \pm 0.09$ \\
5 & $1.15 \pm 0.11^{\mathrm{c}}$ & $1.24 \pm 0.15^{\mathrm{a}}$ & $1.62 \pm 0.04$ & $1.72 \pm 0.05$ \\
6 & $1.23 \pm 0.06^{\mathrm{c}}$ & $1.58 \pm 0.10$ & $1.68 \pm 0.07$ & $1.63 \pm 0.08$ \\
7 & $1.52 \pm 0.07$ & $1.21 \pm 0.16$ & $1.61 \pm 0.08$ & $1.62 \pm 0.06$ \\
10 & $1.63 \pm 0.02$ & $1.70 \pm 0.03$ & $1.40 \pm 0.11$ & $1.71 \pm 0.08$ \\
14 & $1.61 \pm 0.12^{2}$ & $1.68 \pm 0.02$ & $1.83 \pm 0.04$ & $1.72 \pm 0.06$ \\
21 & $1.56 \pm 0.09^{\mathrm{a}}$ & $1.67 \pm 0.06^{\mathrm{a}}$ & $1.83 \pm 0.06$ & $1.86 \pm 0.04$ \\
28 & $1.52 \pm 0.07^{\mathrm{b}}$ & $1.36 \pm 0.08^{\mathrm{a}}$ & $1.66 \pm 0.03^{\mathrm{a}}$ & $1.77 \pm 0.03$ \\
\hline
\end{tabular}

Values with superscripts are significantly different from the corresponding control value; ${ }^{a} P<0.05,{ }^{b} P<0.02,{ }^{c} P<0.01$.

the recovery period. There was a significant $(P<0.05)$ decrease of ATP concentration in the testes of animals in Groups 1 and 2, but testicular ATP concentrations in Group 3 testes were unaffected.

Few significant changes occurred in the kidney or liver. Organ weights, ATP concentrations, and histological appearances were normal in both organs. There was no effect of fluoroacetate on either the amount of protein excreted or the concentration of protein in urine. Small but significant $(P<0.05)$ accumulations of citrate were noted in the kidneys of Group 1 rats on Days 1 and 4 and of Group 2 rats on Day 6. No significant accumulation of citrate was noted in the livers of any of the treated animals (Table 3 ).

\section{Discussion}

Smith, Gardner, Yuile, de Lopez \& Hall (1977) found that a dose of 20 p.p.m. fluoroacetate produced only a slight retardation in growth rate for the first 7 days of treatment and little effect thereafter. Higher concentrations produced severe retardations in growth rate (Miller \& Phillips, 1955). Similar results were seen in the present experiment. In our experience the testis was the organ most vulnerable to fluoroacetate poisoning: there was marked citrate accumulation, depression of ATP levels, and weight, while little change was seen in the liver or kidney. The elevated testicular citrate levels are evidence of fluorocitrate-mediated inhibition of cis-aconitase. The degree of inhibition appears to be dose dependent since the highest concentration of fluoroacetate in the drinking water produced the earliest and greatest increase in citrate.

The depression of testicular ATP levels may indicate that the tricarboxylic acid cycle was sufficiently inhibited to prevent adequate production of ATP, which in turn may contribute to the testicular damage.

The decline in testicular weights is associated with the loss of testicular cellular elements and tubular volume. Testicular degeneration associated with aliphatic fluorine-containing compounds was first described by Mazzanti et al. (1964) in experiments with fluoroacetamide. In these and subsequent experiments using fluoroacetate, Mazzanti et al. (1965) noted testicular atrophy with damage to the seminiferous epithelium but not the Leydig cells. Mazzanti, Lopez \& Del Tacci (1968) also noted complete testicular recovery within 168 days after treatment with fluoroacetamide. Hashimoto, Makita, Miyata, Noguchi \& Ohta (1968) noted similar damage in rats 
given $N$-methyl- $N$ (1-naphthyl)-fluoroacetamide for 6 months. Steinberger \& Sud (1970) have found that $5-20 \mathrm{mg}$ fluoroacetamide $/ \mathrm{kg}$ diet produced only degeneration of late spermatids, with no apparent damage to the spermatocytes after 28 days of treatment. However, $50 \mathrm{mg}$ fluoroacetamide $/ \mathrm{kg}$ diet caused more extensive degenerative changes, similar to those seen in the present study. Steinberger \& Sud (1970) concluded that, at sufficiently low concentrations, fluoroacetamide would produce its effect on only one specific cell stage.

The testicular damage caused by fluoroacetate does not appear to be unique. For example, nitrofurans and manganese primarily injure spermatocytes and spermatids at doses that seemingly have little other effect on the animal (Paul, Paul, Kopko, Bender \& Everett, 1953; Uematsu, 1966; Husain, Seth \& Chandra, 1976). All of these poisons interfere with some aspect of glycolysis or the tricarboxylic acid cycle in the testis at levels which seemingly do not affect other tissues. The sensitivity of the testis may reflect its constant need for an ample supply of ATP and its inability to use pathways other than the Embden-Meyerhof tricarboxylic acid cycle to produce sufficient ATP. The more mature testicular elements, e.g. spermatocytes and spermatids, appear to depend almost entirely on the Embden-Meyerhof pathway and the tricarboxylic acid cycle for energy production (Means \& Hall, 1968; Free, Massie \& VanDemark, 1969) and apparently are unable to compensate for any blockage in the pathway. Why manganese and nitrofurans first affect the spermatocytes, whereas fluoroacetamide and fluoroacetate show spermatid specificity is not evident. Failure of the testes of rats treated with 6.6 and 20 p.p.m. fluoroacetate to regenerate completely has been noted. Regeneration did progress up to development of spermatids or spermatozoa in some tubules, but residual damage was present in others. Many early spermatids did not appear to be able to continue their maturation process but instead formed giant cells and subsequently degenerated. The presence of abundant 'tangles' of Sertoli cell cytoplasm may merely represent an 'unmasking' of this cytoplasm secondary to germinal cell depletion or may indicate a primary (due to fluoroacetate) or secondary (cell hypertrophy) effect. If this cellular alteration is a fluoroacetate-induced effect, it might relate to an inability of the Sertoli cells to support the developing spermatids, thus causing them to degenerate. Elftman (1963) noted that early spermatids appear to attach to Sertoli cells between stages III and VII. It is at these stages that the giant cells are being formed.

Fluoroacetate produced few significant changes in the hepatic or renal characteristics measured. The slight increase in renal citrate values indicates that there was some fluorocitratemediated inhibition of aconitase characteristic of fluoroacetate poisoning but this inhibition was apparently not sufficient to cause altered citrate or ATP values or tubular degeneration. Thus, of the three organs studied the testis is most sensitive to fluoroacetate poisoning.

This research was supported by USPHS-NIH Toxicology Training Grant 5-T01-GM-01781, NIEHS Grants ES-00779 and ES-01247 and by the Department of Energy contract at the University of Rochester Biomedical and Environmental Research Project, and has been assigned Report No. UR-3490-1119.

\section{References}

Buffa, P., Guarriera-Bobyleva, V \& Pasquali-Ronchetti, T. (1972) Biochemical effects of fluoroacetate poisoning in rat liver. In Carbon-Fluorine Compounds: Chemistry, Biochemistry, and Biological Activities, pp. 303/362. Elsevier, Amsterdam.

Elftman, H. (1963) Sertoli cell and testicular function. Am. J. Anat. 113, 25-33.
Free, M.J., Massie, E.D. \& VanDemark, N.L. (1969) Glucose metabolism by the cryptorchid rat testis. Biol. Reprod. 1, 354-366.

Hashimoto, Y., Makita, T., Miyata, H., Noguchi, T. \& Ohta, G. (1968) Acute and subacute toxicity of a new fluoride pesticide, N-methyl-N-(1-napthyl) fluoroacetamide. Toxic appl. Pharmac. 12, 536-547. 
Husain, R., Seth, P. \& Chandra, S. (1976) Early inhibition of succinate dehydrogenase by manganese in rat gonads. Bull. Env. Contam. \& Toxicol. 16, 118-121.

Leblond, C.P. \& Clermont, V. (1952) Definition of the stages of the cycle of the seminiferous epithelium in the rat. Ann. N.Y. Acad. Sci. 55, 548-573.

Lowry, O.H., Rosebrough, N.J., Farr, A.L. \& Randall, R.J. (1951) Protein measurement with the Folin phenol reagent. J. biol. Chem. 193, 265-275.

Mazzanti, L., Lopez, M. \& Berti, M.G. (1964) Selective destruction in testes induced by fluoroacetamide. Experientia 20, 492-493.

Mazzanti, L., Lopez, M. \& Berti, M.G. (1965) Atrofia del testiculo produtta dal monofluoroacetato sodico vel ratto albino. Experientia 21, 446-447.

Mazzanti, L., Lopez, M. \& Del Tacci, M, (1968) La rigenerazione del testicolo atrofico da fluoroacetamide. Experientia 39, 258-259.

McDowell, E.M. (1972) Light and electron microscopic studies of rat kidneys after administration of citric acid cycle inhibitors in vivo. I. Effects of sodium fluoroacetate on the proximal convoluted tubule. $A \mathrm{~m}$. J. Path. 66, 513-541.

Means, A. \& Hall, P. (1968) Protein biosynthesis in testis. II. Role of adenosine triphosphate (ATP) in stimulation by glucose. Endocrinology 83, 86-96.
Miller, R. \& Phillips, P. (1955) Effect of feeding fluoroacetate to the rat. Proc. Soc. exp. Biol. Med. 89, 411-413.

Moellering, H. \& Gruber, W. (1966) Determination of citrate with citrate lyase. Analyt. Biochem. 17, 369376.

Pashley, D. (1970) Pathways of renal substrate metabolism by dog kidney cortex, in vitro: evidence for $a$ metabolic component in renal regulation of body fluid pH. Ph.D. thesis, University of Rochester, Rochester, New York.

Paul, H., Paul, M., Kopko, F., Bender, R.C. \& Everett, G. (1953) Carbohydrate metabolism studies on the testis of rats fed nitrofurans. Endocrinology 53, 585592.

Peters, R.A. (1952) Lethal synthesis (Croonian Lecture). Proc. R. Soc. B 139, 143-167,

Smith, F.A., Gardner, D.E., Yuile, C.L., de Lopez, O. \& Hall, L.L. (1977) Defluorination of fluoroacetate in the rat. Life Sci. 20, 1131-1138.

Steinberger, E. \& Sud, B.N. (1970) Specific effect of fluoroacetamide on spermatogenesis. Biol. Reprod. 2 , 369-375.

Uematsu, K. (1966) Testicular changes of rats induced by nitrofurazone. A light and electron microscopy study. Med.J. Osaka Univ. 16, 287-306.

Received 11 September 1978 